\title{
Язык как зеркало сознания постсоветского человека. Проза Романа Сенчина
}

\author{
Abstract \\ Language as the Mirror of Awareness of Post-Soviet Human. Roman Senchin`s Prose
}

The thesis proposed and proved in this article is the conviction that the language of the heroes created by contemporary Russian prose writer, Roman Senchin, copy the type of Russians` awareness, which literary scholars, culturologists and sociologists name postsovieticus. In order to justify the thesis the views of Anna Shor-Churnovska, who joins many features and creates the image of post-Soviet awareness, are presented. Among others, the scholar mentions the imitation of Russian, Soviet and Western models, suspicion, fear, disappointment in the reality and surroundings, passivity, lack of sense of responsibility for ourselves and the country. The second part of the article the analysis of the characters' language in Roman Senchin's works (short stories, tales, novels) was conducted and on this ground the type of created hero was diagnosed. Words and phrases, which dominate in this character's language allow to interpret the hero as clearly manifesting features of post-Soviet awareness.

Keywords: postsovieticus, the latest Russian prose, Roman Senchin, language, awareness.

Роман Сенчин - современный русский прозаик, представитель так называемого нового реализма, документирующий и отражающий в своих произведениях жизнь на рубеже тысячелетий со всеми оттенками и нюансами. По словам русского литературного критика Сергея Белякова, «Россию девяностых и нулевых будут изучать по рассказам и повестям Сенчина, как мы изучаем Францию XIX века по романам Оноре де Бальзака и Эмиля Золя».

Сразу отметим, что предметом особого наблюдения русской литературной критики, высказывающейся о прозе автора Eлтышеевых (2009), является созданный писателем герой. Елена Погорелая утверждает, что герой Сенчи-

1 С. Беляков, Роман Сенчин: неоконченный портрет в сумерках, «Урал» 2011, № 10. Цит. по: Все о Сенчине. В лабиринте критики, сост. и предисл. В. Огрызко, Москва 2013, с. 388. 
на «замыкает собой ряд героев так называемого lost generation»². Похожее мнение у Ильи Кирилова, который уточняет при этом характеристику сенчинского героя следующим образом: «Молодые люди, русские, бежавшие из национальных окраин, униженные в армии, несостоявшиеся в быту, истощенные нищетой, неудачники в любви - далеко не исчерпывающий список бедствий его героев» ${ }^{3}$. В свою очередь, Максим Артемьев отмечает эволюцию героев Сенчина на протяжении 15 лет литературной деятельности писателя - с середины 1990-х по 2011-й год, когда был опубликован роман Информаичи:

Его герои меняются со временем, и мы уже можем прослеживать их путь [...] с середины девяностых. Тогда они были нищими студентами в общаге, затем стали малопривлекательными мерчандайзерами, офисными сидельцами либо не находящими себя в жизни полуинтеллигентами, пьющими и ширяющими. Сегодня, ближе к сорока, некоторые из них достигли материального благополучия ${ }^{4}$.

Среди других определений, которыми русская литературная критика характеризирует героев Сенчина, отметим следующие: «самый настоящий социальный тип» ${ }^{5}$, «апатичный герой» ${ }^{6}$, «дегенерат» ${ }^{7}$, «одинокий человек, мучительно страдающий от сознания собственного, бесконечного 'опоздания'» ${ }^{8}$.

Согласно предлагаемому нами тезису, героев писателя роднит, в основном, постсоветский тип сознания, проявляющийся не только в способе их функционирования, но и в их словарном запасе - нельзя забывать, что Роман Сенчин в ряде произведений создаёт словесную реальность России после 1991 года, независимо от географии «расселения» своих персонажей - будь то захолустье или Петербург с Москвой.

Вопрос о содержательном наполнении определения homo postsoveticus сложен и всё ещё открыт. Исследованием феномена и поиском ответа на этот вопрос занимаются как социологи, психологи, антропологи, историки, так и некоторые русскоязычные писатели‥ Авторы книги Постсоветский человек и общество отмечают:

2 Е. Погорелая, Путь чувственности к духу, «Октябрь» 2008, № 5. Цит. по: Все о Сенчине ..., c. 231 .

3 И. Кириллов, Похвала бедности, Цит. по: Все о Сенчине..., с. 293.

4 М. Артьемев, Свидетель, а не инсайдер, Цит. по: Все о Сенчине..., с. 423.

5 С. Беляков, Призрак титулярного советника, «Новый мир» 2009, № 1. Цит. по: Все о Сенчине..., с. 237.

6 В. Пустовая, Иск маленькому человеку. Цит. по: Все о Сенчине..., с. 313.

О. Орлова, Чужой Сенчин. Эстетика остранения. Цит. по: Все о Сенчине..., с. 183.

8 А. Рудалёв, Утренняя звезда, «Завтра» 2009, № 5. Цит. по: Все о Сенчине ..., с. 241.

9 Ср. например высказывание Б. Сорокина и С. Алексиевич: «[...] я разочаровался в человеке постсоветском больше, чем в советском. Потому что в советском человеке была некая надежда - что он сможет рано или поздно преодолеть в себе вот это „советское, слишком советское", что это кончится вместе со строем. Сейчас понятно, что в XX веке произошли такие мутации, сопровождающиеся массовым террором, что, собственно, генетическая жертва этой страшной селекции - постсоветский человек не только не хочет выдавливать из себя этот советский гной, а напротив, осознает его как новую кровь. Но с такой кровью он становится зомби. Он не способен создать вокруг себя нормальный социум. Он создает театр абсурда», 
В первые годы после краха советской системы среди более образованной части российского общества были довольно широко распространены представления о том, что новое поколение, социализированное уже в других условиях, окажется носителем совершенно иных ценностей, будет характеризоваться другой этикой, мотивироваться иначе, чем их родители и деды ${ }^{10}$.

Создаётся, однако, впечатление, что в таком видении процесса формирования мышления не учитывается то обстоятельство, что постсоветский человек не будет формироваться «с чистого листа», следственно, многие его черты будут тесно связаны с типом личности советских времен. Не учитывается также, что поступательное развитие невозможно без преодоления советского опыта, рефлексии и называния вещей своими именами. Психолог и социолог Анна Шор-Чудновская в статье Понять постсоветского человека замечает:

[...] антропологический тип homo postsoveticus - это человек, которому по каким-то причинам не удается покинуть советскую действительность. Он охвачен своего рода фантомным состоянием, его сознание продолжает по-родственному относиться к иру, которого больше нет, оно черпает из него ориентиры, вопросы и ответы ${ }^{11}$.

Исследуя специфику постсоветскости и ориентируясь на высказывания ряда представителей интеллигенции, в частности, Андрея Колесникова, Евгения Альбаца, Альберта Бандуры, Ханны Арендт, Михаила Гефтера, Александра Эткинда, Макса Вебера, Юрия Левады и Ольги Седаковой, А. Шор-Чудновская старается дать обобщенную характеристику сознания постсоветского общества. Так, к перечисленным ею чертам постсоветского человека относятся:

- имитация - как чужого (образцы, заимствованные у Запада или Востока), так и своего опыта, взятого из времён царской России или из советского прошлого. Иначе

В. Сорокин, Постсоветский человек разочаровал больще, чем советский, http://kommersant.ru/ doc/2786007 (доступ: 10.11.2016).

«Люди в 90-ые годы хотели свободы. А на самом деле потом выяснилось, что они хотели лучшей жизни, они не знали, что такое свобода. Все говорили о свободе, кричали «Свобода, свобода!», а на самом деле никто не знал, что это такое, и никто не был к этому готов. Или, может, мы слишком рано ушли с площадей. Во всяком случае, сегодня мы живем с чувством поражения. Нужно понять причину поражения. Мы были очарованы этим воздухом свободы, которого, как оказывается, и не было.

Ельцин быстро стал царем Борисом, демократы превратились в олигархов и бизнесменов... Очень мало людей оказалось в выигрыше. Эта идея будет смущать людей еще долго. Постсоветский человек был брошен в одиночество, он сам должен был выживать и сам вообще делать эту работу по пониманию того, что происходит. И в результате, как вы видите, вот такой откат назад - снова сталинские музеи, идеи. Так что надо рефлексировать, а не просто ругать что-то, надо обдумывать и серьезно говорить. Нельзя выйти из лагеря и сразу стать свободным. Свобода - это долгий путь», С. Алексиевич, Русский рай закончился кровью, http://ru.rfi. fr/ukraina/20160413-svetlana-aleksievich-russkii-rai-zakonchilsya-krovyu (доступ: 10.11.2016).

10 Л.Д. Гудков, Б.В. Дубин, Н.А. Зоркая, Постсоветский человек и гражданское общество, Москва 2008, с. 11, http://msps.su/files/2015/04/post-soviet_man.pdf (доступ: 10.11.2016).

11 А. Шор-Чудновская, Понять постсоветского человека, «Неприкосновенный запас» 2009, № 6, http://magazines.russ.ru/nz/2009/6/an16.html (доступ: 10.11.2016). 
- поверхностное, механическое копирование без освоения образца и его смысла, без подлинного развития;

- подозрительность и страх предательства, на которых в постсоветском обществе базирует отношение к другим: «свой» может предать так же, как «чужой»;

- отсутствие саморефлексии;

- несозидательное и равнодушное отношение к миру;

- отсутствие ответственности за благоустройство общественной жизни;

- разочарование в человеке, в самих себе;

- пассивность; отсутствие цели, проекта, долгосрочного планирования как на частном, так и на государственном уровне;

- приобщение к массовой потребительской культуре ${ }^{12}$.

Названная Шор-Чурновской имитация - одна из черт, свойственных ментальности героев Сенчина. Она проявляется как на поведенческом, так и на языковом уровнях. В частности, с этим связано наличие в речи героев заимствований, в основном, англицизмов: с одной стороны, это, вошедшие в русский язык названия неведомых ранее реалий: «компьютер», «эмейл», «ноутбук», «рейтинг»; с другой - англицизмы «тинейджеры», «френды», «митинг», «ољкей!», «супер», «уикенд», употребление которых не является оправданным, ибо в русском языке для передачи их значения существуют соответствующие лексические единицы. Ещё одной важной чертой речевого облика сенчинских героев является наличие в их языке слов и выражений бандитского жаргона («в падлу», «бабло»), в частности, вульгаризмов «новых русских», языковая «норма» которых сформировалась, по мнению Максима Кронгауза, «под влиянием американской гангстерской мифологии» ${ }^{13}$.

Общеизвестно, что употребление вульгаризмов является лакмусовой бумажкой воспитания и образования говорящего, с особой остротой указывает на его способ восприятия мира и окружающих, в чей адрес он употребляет грубости, табуированную лексику. Следующая черта, указывающая на имитацию героями Сенчина советского опыта - презрительно-высокомерное, оскорбительное отношение к широко понимаемому «подчиненному». «Новый русский» у Сенчина - не столько предприниматель нового типа, сколько власть нового типа, человек, который своими манерами напоминает бывших правителей, генсеков, милиционеров - всех тех, кто в советское время подчинял своей воле других, совершенно не делая различий между злом и добром. В данном контексте уместным будет напомнить, что, согласно проведённому Иваном Климовым анализу результатов опроса относительно того, какая первая ассоциация у русского со словом «хамство», многие считают, что «склонность 〈хамить, общаться, как с быдлом〉 присуща людям, наделенным властью» ${ }^{14}$.

В романе Нубук (2003) Сенчин создаёт образы мелких предпринимателей, пытающихся войти в полный хаоса и опасностей мир русского бизнеса

12 CM. ibid.

13 См. М. Кронгауз, Русский язык на грани нервного срыва, Москва 2007, с. 25-26.

14 И. Климов, О хамстве и хамах, http://corp.fom.ru/uploads/socreal/post-154.pdf и http:// bd.fom.ru/report/cat/home_fam/of054126/printable/ (доступ: 10.11.2016). 
1990-ых, «когда за гроши можно было приватизировать целые предприятия» ${ }^{15}$. Языковой портрет этих молодых людей включает три важных явления:

- присутствие как мотивированных, так и немотивированных заимствований из английского языка [«экстрим» (с.104), «о'кей» (с. 142), «офис» (с. 176), «тинейджеры» (с. 104)] $]^{16}$;

- употребление слов «новорусского языка», т.е. старых слов в новом значении ${ }^{17}$ - например, «крыша» ${ }^{18}$;

- нагромождение лексики со стилистически сниженной окраской и вульгаризмов [«хреново» (с. 102, 141, 229), «ни фига» (с. 150, 255), «фигня» (с. 185), «деньги просрать» (с. 184, 240), «Как задницу, блин, подтерли...» (с. 195), «бухал по полной, да?» (с. 266), «Сука! Дура!» (c. 270, 271), «Кретин, сучонок» (с. 283), «втянуть в дерьмо» (с. 289), «попасть в дерьмо» (с. 291), «- Везде долги, сука, весь в говне!» (c. 292)].

Первое из указанных явлений - заимствования - свидетельствует об имитации западного опыта, в то время как второе и третье явления уходят корнями в опыт советский, ибо придание словам новых значений, а также грубость, сквернословие и оскорбления - брутализация языка - возникли и начали приобретать массовый характер уже в первые послереволюционные годы. Эти явления, в частности, в своих сатирических произведениях зафиксировали Михаил Булгаков и Михаил Зощенко. В свою очередь, русский писатель, литературовед и критик Андрей Синявский в работе Ocнoвы советской цุивилизации обращает внимание на то, что особый психологический тип «нового человека», выработанный общественной и государственной системой после 1917 года, «утратил все или почти все добрые свойства, которые присущи простым людям, а взамен приобрел наглость, развязность, высокомерие, готовность судить обо всем на свете и все объяснять, разумеется, самым примитивным способом» ${ }^{19}$. Синявский упоминает также о господствующей в «новоязе» тенденции придавать старым словам новые значения: например, слово «господин» после 1917 года потеряло окраску вежливости и почтения и стало способом выразить данному лицу недоверие, оскорбить, заподозрить в контактах со старым порядком ${ }^{20}$.

Интересное замечание по поводу способа высказывания сенчинских героев делает российский литературный критик и литературовед Ирина Роднянская. Анализируя нашумевший роман Сенчина Eлmылшевы, исследователь замечает, что употребляемое капитаном милиции Николаем Елтышевым, одним из главных героев произведения, слово «блатная» («Но многие завидовали Николаю Михайловичу. После длинной очереди, нешуточной

15 Р. Сенчин, Нубук, Москва 2003, с. 137.

16 Ibid.

17 См. М. Кронгауз, ор. cit., с. 23.

18 «[...] И это подтолкнуло Володьку заняться обувью, предварительно, конечно, найдя надежную 〈крышу〉 [...]», см. Р. Сенчин, Нубук..., с. 138.

19 А. Синявский, Основы советской циивилизации, Москва 2002, с. 213.

20 Ibid., c. 302. 
борьбы ему удалось получить должность, считавшуюся блатной: дежурный по вытрезвителю») ${ }^{21}$ взято из доперестроечного лексикона, а профессиональные обычаи героя (речь идет о совершаемых Елтышевым кражах в вытрезвителе), получили распространение уже в 1970-е. Отсюда вывод Роднянской: «Ниточка социальной аномии, беззакония тянется с отдельных времен как 〈дело житейское»» 22 .

Эффектом подозрительности и страха предательства - упомянутых выше составных постсоветского сознания, на которые указывает Шор-Чурновская - является неискренность повседневных межличностных контактов. Рассказ Эфир (2000) представляет собой один день из жизни Марины Стрельцовой, молодой женщины, несколько лет назад переселившейся из далекой провинции сначала в Ленинград, а затем в Москву. Марине, по ее собственным словам, «повезло» ${ }^{23}$ : она работает в телекомпании, неплохо зарабатывает по столичным меркам и живёт в собственной двухкомнатной квартире. В этой квартире Марина встречается с богатым женатым мужчиной, с которым ведёт непринужденные разговоры, пьет вино и занимается сексом. Для Марины важно, что этот мужчина «с пустыми руками не приходит» ${ }^{24}$. Неискренность отношений героев нетрудно заметить, анализируя их диалоги. Процитируем один из них:

- А я тебе приготовил подарок, мурлуська - объявил Борис и достал из кейса пеструю коробочку. - Ты, кажется, давно хотела карманный компьютер... Вот, пожалуйста «Покет Пи-Си». [...]

- Спасибо, милый! Неужели это мне? (с. 99).

Появляющиеся в диалоге Марины и Бориса ласкательные слова и выражения благодарности становятся элементом игры, правила которой Марина хорошо знает и соблюдает. Игру эту можно назвать «обменом», соответствующим следующему определению: «Процесс движения товаров как форма распределения производимых обществом ценностей» ${ }^{25}$. Диалоги героев «рутинны», лишены искренних положительных эмоций и спонтанности, что подтверждается комментарием повествователя: «[...] Марина научилась отвечать ему» ${ }^{26}$. Используемые любовниками слова и обороты не несут подлинной смысловой нагрузки, а являются принимаемой обоими ложью: так, после встречи Борис уходит к себе домой, к жене и детям, и прощаясь с Мариной, говорит: «Я всегда твой» ${ }^{27}$.

Следует, однако, заметить, что герой, преуспевающий или хотя бы ориентированный на карьерный успех, на «модность» и «новорусский» стиль

21 «Но многие завидовали Николаю Михайловичу. После длинной очереди, нешуточной борьбы ему удалось получить должность, считавшуюся блатной: дежурный по вытрезвителю», см. Р. Сенчин, Елтылеевы, Москва 2011, с. 8.

22 И. Роднянская, Род Атридов. Цит. по: Все о Сенчине..., с. 345.

23 Р. Сенчин, Эфир, в кн.: А. Сенчин, На черной лестнице. Рассказы, Москва 2011, с. 95.

24 Ibid., c. 97.

${ }_{25}$ См. «обмен» на: http://www.gramota.ru/slovari/dic/?word=обмен\&all=x (доступ: 12.11.2016).

26 Р. Сенчин, Эфир..., с. 105.

27 Ibid., c. 109. 
жизни, схожий с представленном в рассказе Эфир - не самый типичный для прозы Сенчина. Как справедливо отмечает Михаил Бойко, для писателя характерен взгляд с социального дна ${ }^{28}$, что означает, что созданные им герои являются представителями тех, кто не сумеет, не умеет, не хочет, не в силах - говоря словами Елтышева - «вырваться вперед многих» ${ }^{29}$. Перечитывая произведения Романа Сенчина, легко заметить, что его герои - чаще всего оказавшиеся в большом городе провинциальные дурочки; ведущие унылую, безрадостную жизнь беспутные молодые люди; учителя, переквалифицировавшиеся в огородников, торгующих на овощном рынке; жители обшарпанных комнатушек в общежитии или тесных «хрущёвок»- все те, кто оказался вне времени, за бортом жизни и благополучия. Важно заметить, что большинство сенчинских героев - люди пассивные, апатичные, со свойственным им постоянным отсутствием цели, проекта, долгосрочного планирования. Как подчёркивает Валерия Пустовая, комментируя роман Eлтылшевы: «Апатия героя способна привести в бешенство не только его отца, но и читателей» ${ }^{30}$.

Сенчинским героям - представителям поколения, кому в 2000-м году уже за сорок - свойственна подозрительность, неверие в готовность другого человека позаботиться о тех, кто нуждается в помощи. Так, мать из рассказа Письмо из деревни в письме переехавшему в город сыну дает ему следующий совет: «Да и сам не знаешь, как там, в большом-то городе - ведь что случиться, никто не поможет, мимо пройдут» ${ }^{31}$. Люди, чьё формирование как личности пришлось на советские времена, были приучены системой не только к ненадёжности и продажности окружающих, но и к тщетности попыток принятия самостоятельных решений, ибо всё решается за них. В быстро изменяющихся реалиях России 1990-х-2000-х годов - внедрения рыночных механизмов и частной инициативы - оказывается, что люди не в состоянии самостоятельно думать, принимать решения, осмыслять происходящее вокруг них. Нагромождение трудностей в связи с курсом на политическую перестройку и последовавшими за ней экономическими экспериментами оборачивается для них тупиком, из которого невозможно выйти, подлинной катастрофой. Упомянутый уже Николай Елтышев (Eлтылшевы) „Подобно многим своим сверстникам"32, разменявшим в начале нового тысячелетия пятый десяток, думает о прошлом как о временах, когда за исполнение обязанностей что-то «давали»: «Дали двухкомнатную квартиру [...]» (c. 5); «[...] участок под гараж долго не давали [...]» (с. 6), а «жизнь текла пусть непросто, но в целом правильно, как должно» (с. 6).

28 М. Бойко, Русский фари. Послесловие к книге Р. Сенчина «День без числа», Москва: «Литературная Россия» 2006. Цит. по: Все о Сенчине..., с. 201.

29 Р. Сенчин, Елтылеевы..., с. 6.

30 В. Пустовая, Иск маленькому человеку..., с. 313.

31 Р. Сенчин, Письмо из деревни, в кн.: Р. Сенчин, Изобилие, Москва 2011, с. 129, подчеркнуто мною - К.Я.

32 Р. Сенчин, Елтылшевы ..., с. 5. 
«Давала» или «не давала», конечно, власть, требующая от граждан жизни в обозначенных рамках, без попыток самостоятельно думать и становиться самодостаточной личностью. Государство боролось не с комбинациями «налево», которые для Елтышева являются «нормой жизни», а с личностью, требующей свободы, счастья согласно собственным представлениям и возможности выбирать жизненный путь. Итак, «поколение Елтышевых-старших» вырастило молодое поколение россиян, которым свойственны страх, повышенная тревожность, безответственность, несамостоятельность и нерешительность в сложных ситуациях. Результат - постоянные попытки убежать от реальности, реализуемые через попадание в алкогольную или наркотическую зависимость. Такой способ восприятия мира, себя и других в этом мире характеризирует не только людей недалёких, но и неплохо образованных молодых людей (довольно большая часть сенчинских героев художники). В большинстве произведений писателя в качестве смысловой доминанты появляются высказывания героев, свидетельствующие о пессимизме, пассивности, неверии в собственные силы и способность преодолеть препятствия. В качестве иллюстрации - несколько цитат:

Из рассказа Афинские ночи:

«[...] в мире нет ничего хорошего ни для меня, ни для тех, кто меня окружает. И надеяться не на что» ${ }^{33}$;

«Мой идеал - анархия, голый индивид на голой земле, но это несбыточно. Все мы рабы государства, пешки...» ${ }^{34}$;

«Вообще все дерьмо одно. Что бы ни начал делать, оказывается дерьмом. До простейшего» ${ }^{35}$.

Из рассказа На кухне:

«Кто я вообще, что? - и плачущим голосом отвечает: - Ничто!»

«Жизнь - болото. Просто, поминаешь, родили, ну и живи. Да, это болото» ${ }^{37}$.

Из рассказа Еще одна ночь:

«А я нигде не работаю, после девятого никуда не пошла - что толку... Мать целыми днями сидит на Торговом, а я валяюсь дома, в мерзкой комнатушке $[\ldots]\rangle^{38}$.

Из рассказа Тоже история:

«И что с нами дальше делать будут - вопрос» ${ }^{39}$.

Из повести Зима:

«Да и что нужно искать в моем положении? В моем непонятном положении... [...] Не знаю... Не знаю, не хочу анализировать $[\ldots]^{40}$;

Из романа Елтылшевы:

«Возможно же как-нибудь и в таких условиях человеком оставаться.

- А как? - Закипятился Юрка. - Подскажи, если знаешь» ${ }^{41}$;

33 Р. Сенчин, Афинские ночи, в кн.: Р. Сенчин, Московские тени, Москва 2013, с. 140.

34 Ibid., c. 154.

35 Ibid., c. 186.

36 Р. Сенчин, На кухне, в кн.: Р. Сенчин, Изобилие..., с. 71.

37 Тамже, с. 72.

38 Р. Сенчин, Еще одна ночь, в кн.: Р. Сенчин, Изобилие..., с. 83.

39 Р. Сенчин, Тоже история, в кн.: Р. Сенчин, На черной..., с. 238.

40 Р. Сенчин, Зима, в кн.: Р. Сенчин, Чего вы хотите?, Москва 2013, с. 13.

41 Р. Сенчин, Елтылеввы ..., с. 115. 
« - Да, надо, соглашался Артем, но по-настоящему не верил, что они в силах что-то здесь, среди этого старья, изменить... $\rangle^{42}$;

«Что мне делать?! - [...] Как тут?... Я не могу!...Жить не хочу! Не могу ничего, не знаю...» $»^{43}$.

Подводя итоги, можно сказать, что большинству героев, выведенных Романом Сенчиным, свойственен постсоветский тип сознания. Отправной точкой нашего исследования поведения героев, позволяющего прийти к такому выводу, стал язык, в котором, как представляется, непосредственно отражён соответствующий способ восприятия мира, самого себя и других людей. Вероятно, именно такое свойство героев писателя стало причиной недоброжелательного отзыва о прозе Сенчина значительной части русской литературной критики и упрёков писателя в стремлении «убить в человеке веру в мир и свое государство» ${ }^{44}$.

\section{Библиография}

Алексиевич С., Русский рай закончился кровью, http://ru.rfi.fr/ukraina/20160413-svetlana-aleksievich-russkii-rai-zakonchilsya-krovyu (доступ: 10.11.2016).

Все о Сенчине. В лабиринте критики, сост. и предисл. В. Огрызко, Москва 2013.

Сенчин Р., Чего вы хотите?, Москва 2013.

Сенчин Р., Нубук, Москва 2003.

Сенчин Р., Елтылшевы, Москва 2011.

Сенчин Р., Изобилие, Москва, 2011.

Синявский А., Основы советской циивилизаџии, Москва 2002.

Сорокин В., Постсоветский человек разочаровал больще, чем советский, http:// kommersant.ru/doc/2786007 (доступ: 10.11.2016).

Гудков Л.Д., Дубин Б.В., Зоркая Н.А., Постсоветский человек и гражданское общество, Москва 2008, с. 11, http://msps.su/files/2015/04/post-soviet_man.pdf (доступ: 10.11.2016).

Шор-Чудновская А., Понять постсоветского человека, «Неприкосновенный запас» 2009, № 6, http://magazines.russ.ru/nz/2009/6/an16.html (доступ: 10.11.2016).

Климов И., О хамстве и хамах, http:/corp.fom.ru/uploads/socreal/post-154.pdf и http://bd.fom.ru/report/cat/home_fam/of054126/printable/ (доступ: 10.11.2016).

Кронгауз М., Русский язык на грани нервного срыва, Москва 2007.

Пономарев Е., Ното postsovieticus. Творчество Александра Зиновьева вчера и сегодня. «Звезда» 1999, № 7.

Skotnicka A., Образ «нового русского» в современной прозе [в:] Wielkie tematy kultury w literaturach stowiańskich, t. 8: Pieniadz, ред. Ł. Skotnicka et al., Wroclaw 2009.

Heller M., Jak kształtowat się człowiek sowiecki, Kraków 2015.

http://www.gramota.ru/slovari/dic/?word=обмен\&all=x (доступ: 12.11.2016).

\footnotetext{
42 Ibid., c. 123.

43 Ibid, c. 185.

44 А. Ганиева, Серым по серому. Цит. по: Все о Сенчине..., с. 335.
} 
